\title{
SUSTAINABLE MANAGEMENT OF CLIMATE CHANGE: THE CASE OF THE MIDDLE EAST AND NORTH AFRICA REGION
}

\author{
ADEL M. AL TAWEEL ${ }^{1 *}$, V. ISMET UGURSAL ${ }^{1}$ AND DONNIE BOODLAL ${ }^{2}$ \\ 1 Dalhousie University, Halifax NS, CANADA \\ 2 The University of Trinidad and Tobago, Point Lisas Campus, Trinidad and Tobago WI, \\ *Corresponding author: al.taweel@dal.ca
}

\begin{abstract}
Climate change is one of the major environmental challenges facing the world. Particularly vulnerable are arid and low-laying coastal areas, conditions that prevail through most of the Middle East and North Africa [MENA]. This region is an economically diverse one, including both the oilrich economies in the Gulf and countries that are resource-scarce in relation to their population. However, with about 23 percent of MENA's population living on less than $\$ 2$ a day, it is imperative that the climate change management strategies adopted be cost-effective and emphasize economic, social and human development while addressing the concerns arising from anthropogenic climate change.
\end{abstract}

Over the past decades several national and international mechanisms were developed in an attempt to reduce the emissions considered to be mainly responsible for climate change, and to assist in coping with the adverse effects that are beginning to occur as a result of climate change. Unfortunately, many of these approaches are presently associated with economic penalties that often adversely affect the socio-economic welfare of the populace, particularly in low-, and medium-income countries. In this regard, it is informative to note the experience recently gained by Trinidad and Tobago [T\&T] in its attempt to reduce GHG emissions without affecting the competitiveness of the industrial and agricultural sectors. Using appropriate decision making tools and a policy environment based on a combination of regulations and incentives, the environmental challenges can be turned into a vehicle for sustainable development.

This paper discusses the factors that need to be considered while developing a sustainable climate change management approach for the MENA region and develops some recommendations that may be essential for achieving the desired climate change mitigation/adaptation actions while minimizing social disruption.Greenhouse gas emissions
Keywords - Climate change, MENA region, Global and regional energy production/consumption trends, Energy and wealth, Need for adaptation, Managing GHG emissions, Sustainable development, Building local capacity.

\section{Nomenclature -}

$\begin{array}{ll}\text { CEBC } & \text { Clean Energy Business Council of the Middle } \\ & \text { East and North Africa } \\ \text { CER } & \text { Certified Emission Reductions } \\ \text { CNG } & \text { Compressed natural gas } \\ \text { EU } & \text { European Union } \\ \text { GCC } & \text { Gulf cooperation council } \\ \text { GDP } & \text { Gross national product } \\ \text { GNI } & \text { Gross National Income } \\ \text { HDI } & \text { Human development index } \\ \text { LED } & \text { Low emission strategies } \\ \text { LNG } & \text { Liquefied natural gas } \\ \text { MAPS } & \text { Mitigation Action Plans and Scenarios } \\ \text { PCGDPI } & \text { Per Capita Gross GDP } \\ \text { PPP } & \text { Purchasing power parity } \\ \text { tpa } & \text { Tonne per annum } \\ \text { T\&T } & \text { Trinidad and Tobago } \\ \text { UN } & \text { United Nations }\end{array}$

\section{INTRODUCTION}

Energy is one of the key commodities required to sustain human existence and advancement and is one of the largest components of the world economy. Consequently, global energy consumption has been rapidly increasing over the past two centuries but the pace of change has recently accelerated due to the increase in the total world's population and the rapid improvement in the standard of living in a large segment of the world's populace. However, the negative environmental aspects associated with the increasing consumption of energy necessitate that such trends be properly managed for the overall benefits of humanity (Brundtland et al. 2010). Climate change is a multi-faceted problem that requires the numerous stakeholders to contribute knowledge, skills and energy to plan for the impacts of a warmer planet and to take action to mitigate rising GHG 
emissions. Such actions must however be based on meeting the socio-economic challenges faced in any particular country/region yet help in achieving the overall objectives of protecting the global environment.

Nowhere are the climate change and sustainability issues more acute than in the MENA countries which are likely to be severely affected by climate change. The predicted rise in temperature and sea level may affect coastal areas, while the current severe water stress is likely to be exacerbated (Cherfane 2010, Ghaddar 2010). Water supply sources in MENA two-thirds of which originate outside the region- are being stretched to their limits threatening to lead to national confrontations over this vital resource. Adapting to climate change is not a new phenomenon for the NEMA region. For thousands of years, the people in this region have coped with the challenges of climate variability by adapting their survival strategies to changes in rainfall and temperature. But over the next century global climatic variability is predicted to increase, and NEMA countries may experience unprecedented extremes in climate (World Bank MENA Region, 2007).

This paper discusses the factors that need to be considered while developing a sustainable climate change management approach for the MENA region. Some of the recommendations developed in this paper may be essential for achieving the desired climate change mitigation/adaptation actions while minimizing social disruption particularly in low-income countries.

\section{THE IMPACT OF ENERGY PRODUCTION AND UTILIZATION ON THE SOCIO- ECONOMIC CONDITIONS IN MENA COUNTRIES}

The evolution of population, prosperity, and energy consumption has been substantially different in different parts of the world, resulting in large disparities amongst nations and regions in terms of wealth and the state of human development. This is particularly evident in the Middle East and North Africa, a region which includes both the energy-rich economies in the Gulf as well as countries that are amongst the poorest in the world. Figure 1 clearly illustrates this phenomenon where the 22 MENA countries considered in this investigation (Algeria, Bahrain, Egypt, Eritrea, Iraq, Israel, Jordan, Kuwait,
Lebanon, Libya, Mauritania, Morocco, Oman, Palestine, Qatar, Saudi Arabia, Somalia, Sudan, Syria, Tunisia, UAE, Yemen) were organized in ascending order in accordance with their economic wealth using the World Bank data for the annual per capita gross domestic product (PCGDP). Although the cost of living variation between the different countries is already taken into consideration through the purchasing power parity [PPP] factor, the value of the per capita GDP was found to vary between these countries by a factor of up to about 150 , thus creating a very difficult situation in which it is virtually impossible to develop a singular strategy that meets the needs of the whole region. Conversely, the presence of countries depicting a wide spectrum of developmental stages can create an opportunity for complementary/synergistic action that can benefit the population of both the wealthy and poor countries. Appropriate strategies and frameworks are however needed in order to achieve such goals.

The discrepancy between the various countries in the MENA region becomes less sever when one utilizes more comprehensive indicators of the socio-economic development stage for any particular country. The Human Development Index [HDI] used in Figure 2 is a composite indicator introduced by the UN in 1990 and provides a better measure of the socio-economic state of development of the populace by combining three basic dimensions: life expectancy, educational attainment (through literacy index and registration combined index) and economic performance (through per capita PPP GNI in international dollars) (UNDP, 2010). The use of this more appropriate indicator reduced the inter-country discrepancy within the MENA region to about 3-fold.

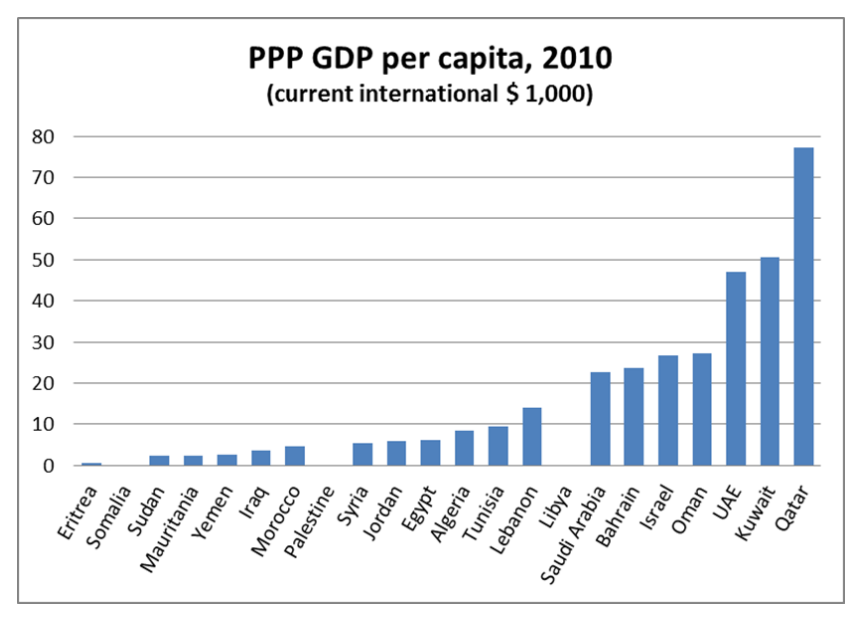

Fig .1. - Intra-region variation of the Per capita GDP 
(Source of data: World Bank Databank, PPP 2011)

However, it is worthwhile to note that whereas only three countries in the region have achieved a high stage of human development (HDI $\geq 0.8$ ), five countries can be considered as still being in a low stage of human development $(\mathrm{HDI}<0.5)$, with the remaining 14 countries being in the moderate stage of human development $(0.5 \leq \mathrm{HDI}<0.8)$.

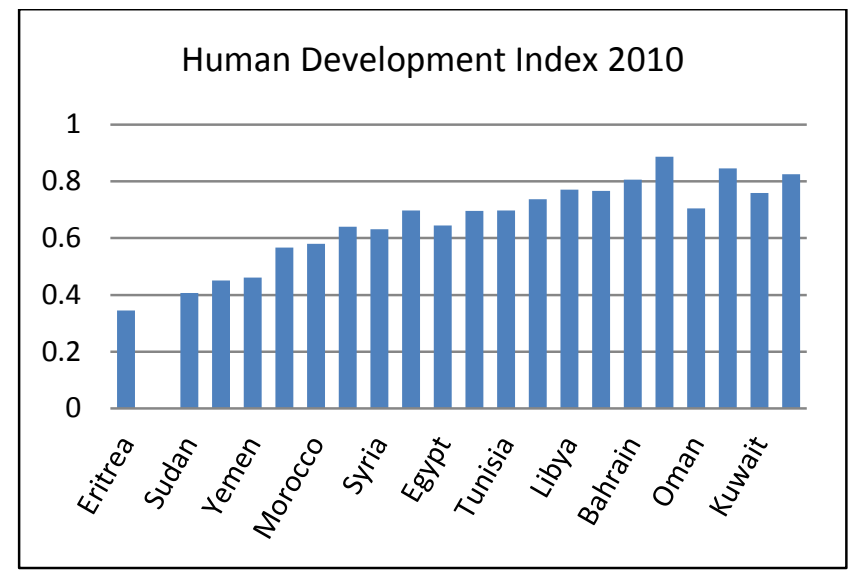

Fig .2. - Regional Variation in the Human Development Index (2011) The scale used for labeling the countries in Fig. 2 resulted in half of the countries being omitted in the formatted version

A significant part of the GDP generated by prosperous MENA countries can be attributed to the production and utilization of non-renewable energy resources (energy-related revenues can be as high as $55 \%$ of the GDP for countries that are primarily oil exporters). Two-thirds of the Organization of Petroleum Exporting Countries (OPEC) are thus located in the MENA region, which has $57 \%$ of the world's proven conventional oil reserves and $41 \%$ of proven conventional natural gas resources. These reserves generated an estimated US $\$ 785$ billion in revenues in 2011 (Fattouh and El-Katiri, 2012) and sovereign investment funds are being increasingly considered as means for ensuring the prosperity of future generations in countries presently endowed with large non-renewable natural resources.

The importance to the energy sector in determining the state of prosperity in MENA countries becomes very clear when one considers the per capita level of GHG emissions and its variation amongst the different countries of the region (Figure 3 ). With the exception of Israel, the most prosperous MENA countries are those with abundant energy resources and energy-based industries (e.g. the processing of petroleum and natural gas as well as petrochemicals).However, the activities associated with the extraction, processing and export of the oil and gas resources, and the rapidly-expanding energy-based industrial sector, are large GHG emitters. Continued development of these energy resources along historic lines is therefore expected to result in exasperating the level of GHG emissions unless certain measures are taken to reduce the overall environmental impact of such development. On the other hand, any viable GHG emission reduction strategy will have to consider the fact that the near-term demand for fossil fuels is predicted to increase as a result of the increase in the world's population, and the increased per capita demand particularly in the rapidly expanding economies such as China, India, and Indonesia. Policies and procedures aimed at implementing cleaner energy extraction/production/utilization are therefore urgently needed, particularly in the wealthy energy-rich countries. Such measures can strongly reduce the environmental impacts of present and future development of energy resources in the region.

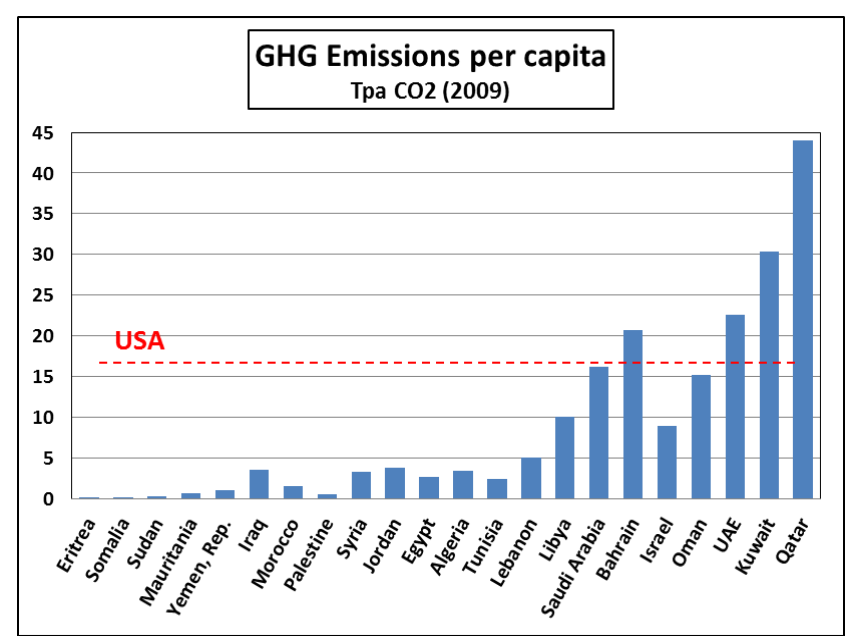

Fig .3. - Regional variation in GHG emissions (Source of data: World Bank Databank)

Previous studies confirmed the existence of strong correlation between the wealth of the citizens of a country and their energy consumption pattern (Sütterlin 2012, Floyd 2012, Estiri et al. 2013), a situation that applies to all countries regardless of their state of human development. Prosperous and developed countries thus have a high level of energy consumption that is used for the production of goods and services, to support the transport and telecommunications sectors, and to achieve a high level of comfort for the citizens. A large part of their 
energy demand is presently supplied (directly and indirectly) by fossil fuels whereas a significant part of the energy demand in low-income countries is supplied by traditional biomass (wood and charcoal). Unfortunately, The increasing use of biomass for energy purposes in middle and low-income MENA countries is one of the major forces driving the desertification process and is driven by the local availability of relatively inexpensive biomass in a world where the price of fossil fuels is relatively high.

As shown in Figure 3 , the same qualitative relationship exists in the MENA region. The average fossil fuel energy consumption in the major oil and gas producers (Bahrain, Iraq, Libya, Qatar, Saudi Arabia, and UAE) are more than 300-fold higher than that in the low-income countries in the region. Unfortunately, these emission levels are also manyfold higher than the present day world-average emission levels (4.6 tpa $\mathrm{CO}_{2}$ Equivalent) as well as the emission levels in developed countries that are strongly dependent on the exploitation of natural resources (Canada $=15.2$ tpa $\mathrm{CO}_{2}$ equivalent; Australia $=18.2$ tpa $\mathrm{CO}_{2}$ equivalent). Amongst the factors contributing to this state of affairs are: the heavy dependence of affluent MENA countries on energy-intensive industries, the export of raw materials with limited local value-added (e.g. crude oil and LNG), and the limited contribution of the agricultural and service sectors to the overall prosperity of the citizens. Concerted efforts have been ongoing to change this situation, but is recommended that special attention be given to the use of low-emission-development routes (e.g. energy efficiency and waste minimization) in order to ensure that the increase in the level of local value added does not result in further exasperating the environmental problems.

The heavy dependence of a country's prosperity and the level of energy resource utilization is reflected in the essentially linear relationship between the per capita GDP and the level of GHG emissions in MENA countries (Figure 4). This is mainly caused by the heavy dependence of affluent MENA countries on energy-intensive industries, the export of raw materials with limited value-added processing, and the limited contribution of the agricultural and service sectors to the welfare of the citizens.

\section{ENERGY CONSUMPTION, POWER GENERATION AND THE STANDARD OF}

\section{LIVING}

Accepting that most countries do not want to suffer a reduction in their prosperity level while attempting to address the climate change challenge, the question becomes how the level of

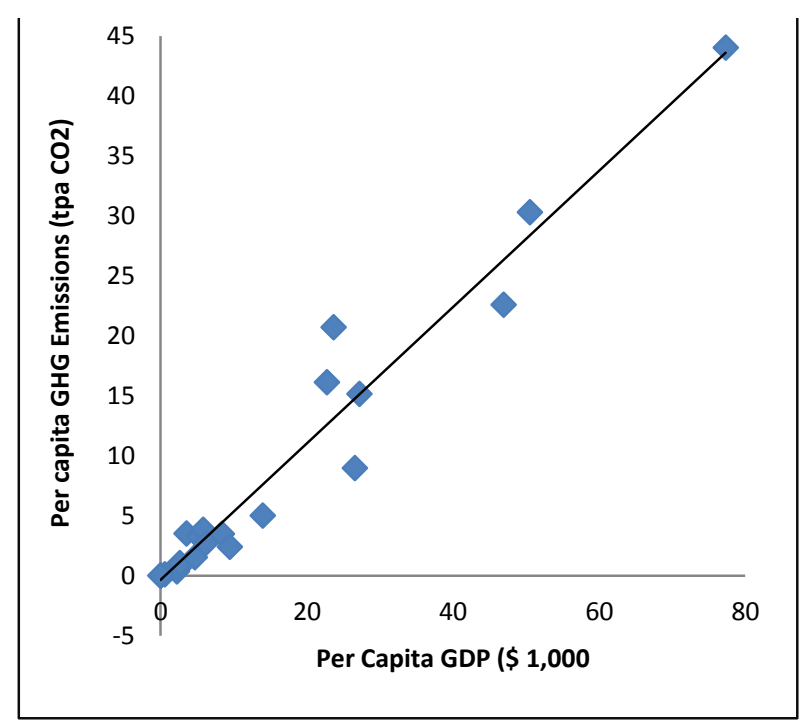

Fig .4. The relationship between PCGDP and the GHG emissions level (Source of data: World Bank Databank, MENA region)

GHG emissions can be reduced while maintaining the prosperity at its present level or even higher. An indication the efficiency by which energy is utilized to generate wealth can be obtained by calculating the amount of GHG emissions associated with every \$ 1,000 PPP GDP produced. This indicator which is frequently used for benchmarking purposes is based on the fact that most of the world's large consumers of energy still rely heavily on fossil fuel for power generation. The large intra-regional variation in the energy use per unit GDP is clearly evident from the results depicted in Figure 5.

An in-depth investigation of the factors contributing to this phenomenon (e.g. internal strife, the contribution of the service sector, the emphasis on high-value added production, the role of the agricultural sector, the role of hydro power) is needed to develop better understanding of the factors hindering the accelerated development of this region as a whole, and to identify novel means by which the prosperity of the region can be enhanced. It is however noteworthy that the prosperous MENA countries are about 3-7 fold less efficient in converting their energy resources into national wealth than it is the case in the USA and EU (Figure 6). Thus, whereas the generation of a $\$ 1,000$ 
of GDP in the former group is associated with the emission of $700-1000 \mathrm{~kg}$ of $\mathrm{CO} 2$ equ., the same is achieved while emitting $100-180 \mathrm{~kg}$ of $\mathrm{CO} 2$ equ. in more developed societies. This suggests that there is a substantial potential for improving the efficiency by which energy resources are converted into revenuegenerating economic activities in the prosperous, hydrocarbon-rich MENA countries. On the other hand, the high energy utilization efficiencies exhibited by the poorest three MENA countries are not indicative of high energy utilization efficiencies but are typical of their developmental stage (HDI < 0.5) where energy (fossil fuels in particular) plays a less significant role in determining the GDP. The very low energy utilization efficiency observed in the case of Iraq in 2009 could most probably be attributed to the internal strife in the country and its negative impact on the GDP. In that regard, it is important to note that although China has been rapidly increasing its power generation capacity to cope with the escalating demand, it has been able to achieve a remarkable increase in the energy use efficiency of energy utilization over the past 30 years. This is largely due to the use of better manufacturing technologies and the gradual shift towards the production of high-value added products and services.

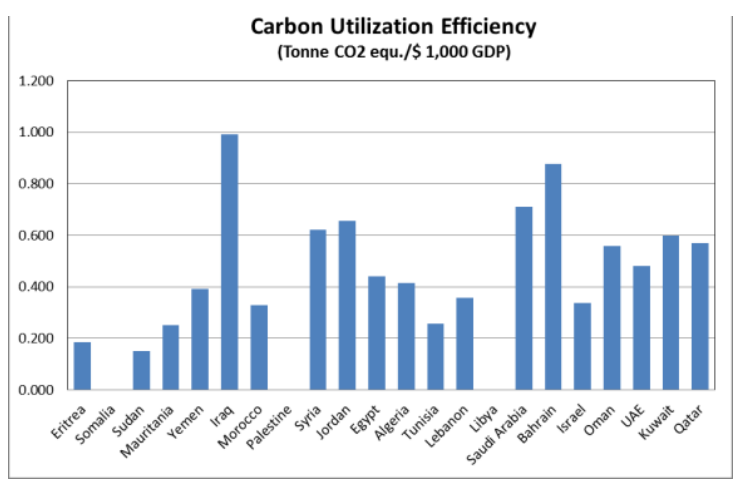

Fig .5. Regional variation in energy utilization efficiency

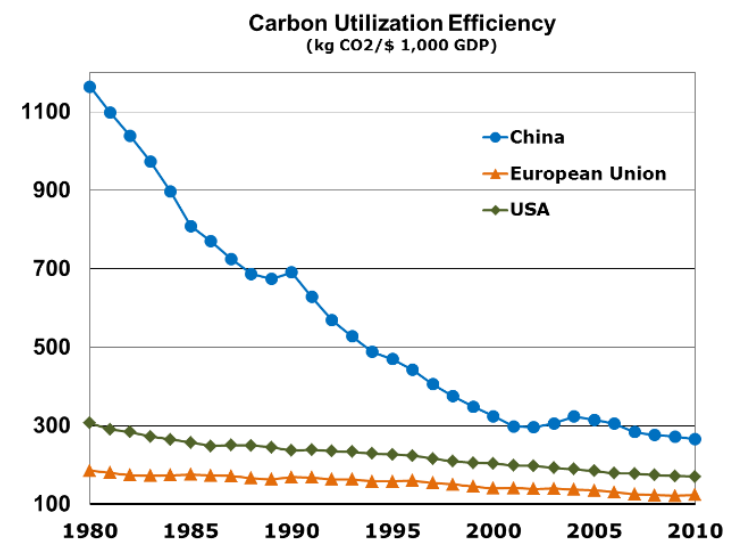

Fig .6. Evolution of energy use per unit of GDP (Source of data: World Bank Databank)

\section{ENERGY CONSUMPTION, POWER GENERATION AND THE STANDARD OF LIVING}

In order to develop sustainable MENA-focused strategies for coping with the problem of climate change it is important that, in a fashion similar to other rapidly-developing regions of the world, the MENA region assumes its responsibility with respect to reducing its GHG emissions while undertaking unquestionably necessary adaptation projects (Verner, 2012). In the meantime, it should also attempt to achieve two important socioeconomic objectives:

- Avoid socially disruptive situations by reducing the large discrepancy in prosperity levels of the citizens within the MENA region.

- Address the need for securing long-term prosperity for the citizens of the countries whose present prosperity levels depend on exhaustible non-renewable energy resources.

The question is how these apparently contradictory demands can concurrently be met particularly by governments that have limited funds and need to spend them in a fashion that addresses urgently needed socio-economic challenges while trying to reduce emissions?. Considering the fact that about $23 \%$ of the population in MENA lives below the poverty level of less than $\$ 2$ a day, a concerted effort aimed at improving the standard of living in the region as a whole is desperately needed if social turmoil is to be minimized. It is however imperative that the strategies adopted emphasize economic, social and human development objectives while addressing the concerns arising from climate change. However, the financial and human resources needed for such an effort can be limiting factors considering the multifaceted needs in the region in a period of budgetary constraints throughout much of the world.

In a recent study based on data from 112 countries (Ugursal, 2013), it was noted that the relationship between the HDI and energy consumption depends very much on the country's developmental stage (Figure 7). Thus, for example, a substantial increase in the per capita energy consumption is needed before any significant improvement can be noted in the human development level can be noted for countries with $\mathrm{HDI}<0.5$. On the other hand, 
significant reductions in the energy consumption levels can be achieved without substantial reduction in the standard of living in countries with $\mathrm{HDI} \geq 0.8$; while, small increases in energy consumption result in substantial increases in the HDI of countries within the moderate $\mathrm{HDI}$ range $(0.5-0.8)$.

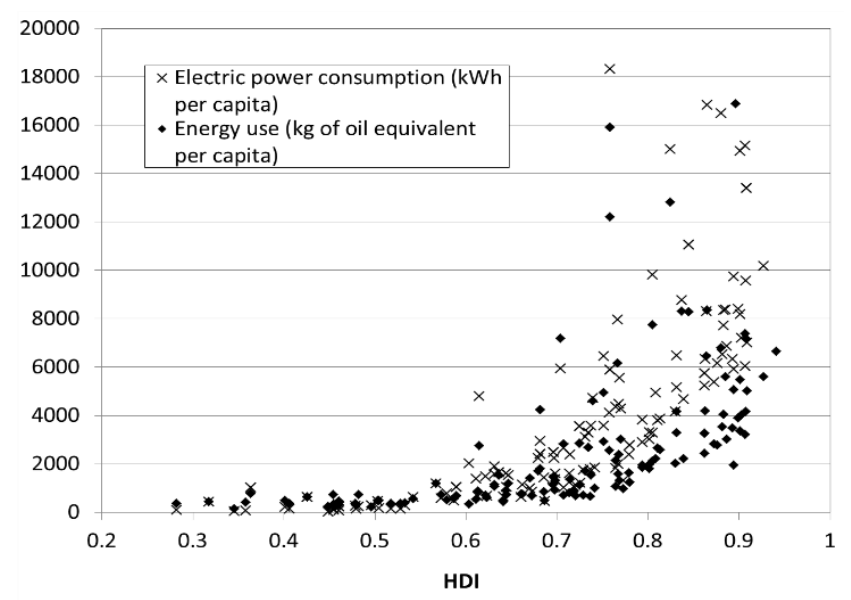

Fig .7. Relationship between a country's HDI and its per capita energy consumption rate (Ugursal, 2013).

It is therefore projected that substantial investment in power generation and utilization will be needed in most of the 19 countries having HDI less than 0.8. Such a massive undertaking will adversely affect climate change with the impact being mitigated if low emission development [LED] strategies are adopted in the new projects and measures for improving the efficiency of existing operations are adopted (Clapp et al., 2010). Considering the fact that the population of the region is in excess of 330 million with an average per-capita GHG emission of 5.85 tpa $\mathrm{CO} 2$ equivalent per year, the full impact of unplanned development is equivalent to adding a GHG emitter that is equivalent to $2 / 3$ that of the USA (until recently, the world's largest emitter).

Innovative means for the planning, financing, execution, and managing of such a major undertaking are therefore needed in order to avoid the adverse impact of combined social, economic, and environmental upheavals. The concept of "Sustainable Development" with its emphasis on balancing the needs of the society with those of the environment in an economically viable fashion represents one of the most promising avenues for achieving the aforementioned balanced objectives. However, the challenge of managing this global problem in a sustainable fashion is quite daunting particularly considering the conflicting interests of the various regions and countries, particularly those at radically different stages of development.

The increase in GHG emissions associated with the accelerated development of low-, and mediumincome MENA countries can be partially compensated by improving the environmental efficiency of the enormous oil and gas sector operating in various MENA countries. Many such countries (e.g. Algeria, Egypt, Iraq, Kuwait, Libya, Oman, Qatar, Saudi Arabia, and UAE) have very large oil and gas operations, a situation that offers the opportunity for achieving significant reductions in GHG emissions at little, or even negative, costs. A review of the GHG mitigation efforts in most of the MENA countries was recently given by Abdel Gelil (2009). Once identified, the private sector may be interested in profitable emission reduction schemes but some additional incentives may be needed for high-risk border line cases. Typical examples are:

- Reducing the wasteful release of undesired energy by-products (e.g. flares).

- Replacing high-carbon fuels with low-cost lowemission alternatives.

- Enhancing the efficiency of power generation plants and power transmission systems,

- Enhancing the efficiency of energy utilization in large industrial operations, and

- Identifying opportunities for reusing some of the $\mathrm{CO} 2$ captured in the many petrochemical plants present in the region for enhancing oil recovery in nearby fields.

It is hard to overemphasize the importance of energy efficiency as an economically-viable tool for mitigating GHG emissions. The experience in many European countries, combined with the recent financial crunch, resulted in the recent adoption by the EU of "Directive 2012/27/EU" on energy efficiency. This Directive establishes a common framework of the promotion of energy efficiency within the EU in order to ensure the achievement of its 2020 target on energy efficiency, and to pave the way for further energy efficiency improvements beyond that date. It also lays down rules designed to remove barriers in the energy market and overcome market failures that impede 
efficiency in the supply and use of energy, and provides for the establishment of indicative national energy efficiency targets for 2020 Marginal MENA cases may be eligible for financial support through various international programs, such as the Clean Development Mechanism [CDM] program and the Global Environment Facility fund. It is however imperative that such border-line project meet the sustainability criteria and urgently addresses the socio-economic needs of the population.

The potential for significantly reducing GHG emissions at little or no cost is not a situation that is unique to MENA and was identified to exist in several countries. For example, it is estimated that a significant reduction in Australian GHG emissions can be achieved (30\% below 1999 levels by 2020) can be achieved without major technological breakthroughs or lifestyle changes. These reductions can be achieved by using existing approaches and by deploying mature or rapidly developing technologies to improve the carbon efficiency of the Australian economy (Gomer and Lewis, 2008) It is, however, essential to redress the imbalance presently existing in the various methodologies used to estimate GHG emissions. For example, equitable mechanisms may have to be developed by which the GHG emissions associated with the production, export, and transport of natural gas $(10-12 \%$ of the carbon content in the case of LNG) can be split between the exporting counties and those which use it to replace coal in power generating plants.

\section{AN EXAMPLE OF A SUSTAINABLE CLIMATE CHANGE MITIGATION EFFORT}

Over the past few years, several national and international mechanisms were developed in an attempt to reduce GHG emissions and to assist in coping with the adverse effects that are beginning to occur as a result of climate change. Unfortunately, many of these approaches are presently associated with economic penalties that often adversely affect the socio-economic welfare of the populace particularly in low-, and medium-income countries. In this regard, it is informative to note the experience recently gained by Trinidad and Tobago [T\&T] in its attempt to reduce GHG emissions without affecting the competitiveness of its industrial and agricultural sectors.
Although the GHG emissions of Trinidad and Tobago are not very large when compared to larger countries (estimated at $53 \mathrm{M}$ tonne $\mathrm{CO} 2$ Equivalent per year in ), it is one of the world's largest GHG emitters per capita (40 tpa CO2 Equivalent in 2009). Initial attempts were made to meet its international obligations, focused on policies/measures similar to those used in developed economies (energy efficient cars, replacing incandescent bulbs etc.). However, a recent inventory of the sources of GHG emissions clearly showed the inability of such simple measures to achieve substantial reductions in GHG emissions (Figure 8), since more than $80 \%$ of the GHG emissions are generated by industrial activities.

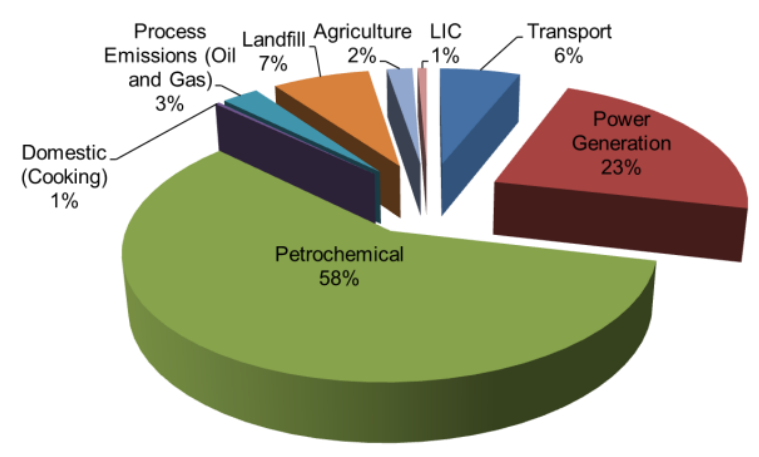

Fig .8. Sources of GHG emissions in T\&T, 2010 (adapted from Boodlal and Al Taweel, 2013)

Conventional environmental management concepts were applied to identify means by which GHG emissions can be reduced without significantly affecting the value of the welfare of the country (Figure 9). Based on the results of an inventory of GHG emissions in T\&T, and the costs associated with each GHG reduction option, an indigenous action plan was proposed (Boodlal and Al Taweel, 2013) which includes identification of the optimal carbon reduction opportunities in the country (Figure 10).

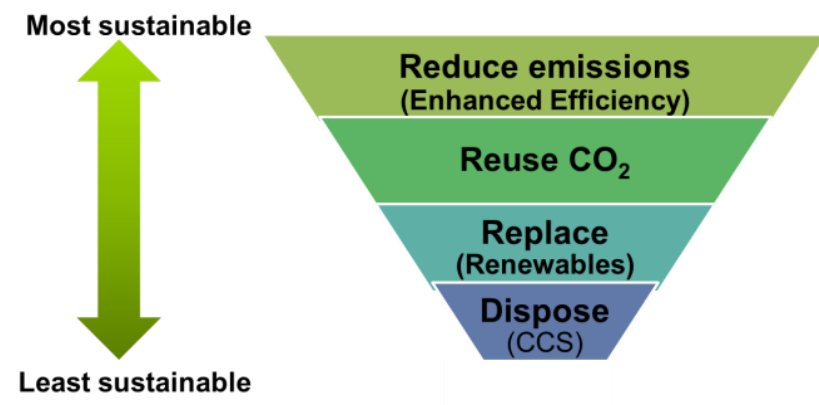

Fig . 9. Identifying the most sustainable GHG reduction strategies 


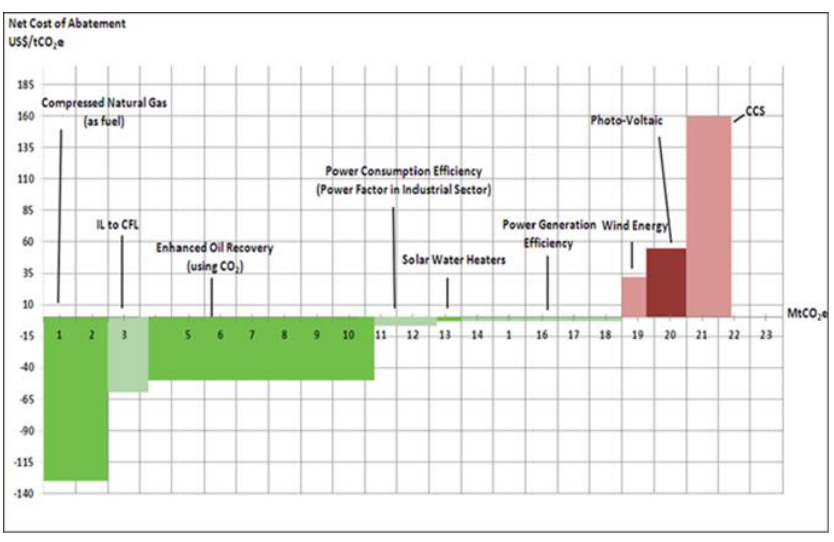

Fig . 10. Cost associated with the various options for reducing GHG emissions in T\&T (adapted from Boodlal and Al Taweel, 2013)

Very conservative cost estimates were used in this study since its primary purpose is to serve as a policy development tool rather than for profitability analysis; yet several negative-cost opportunities were identified (Figure 10). This suggests that the implementation of such measures will be beneficial for the country's economy while, simultaneously, reducing its GHG emissions. A policy environment based on a combination of regulations and incentives was also recommended to attract investment to cost-effective emission reduction measures. In this way, environmental challenges can be turned into economic opportunities and a vehicle for sustainable development. To achieve this goal it is, however, necessary to use appropriate decision-making tools and adopt innovative site-specific solutions that take into consideration the socio-economic welfare of the disadvantaged segment of the population.

The most financially attractive option for reducing GHG emission in T\&T is the replacement of liquid fuels (diesel and gasoline) by compressed or liquefied natural gas. For the past several decades, diesel and gasoline have been heavily subsidized in T\&T in order to facilitate the transport of individuals and goods, particularly for the low-income citizens. The price of liquid fuels has been fixed for many years at the fixed prices of: TT\$ $1.50 /$ liter of diesel, TT\$ 2.60/liter of regular gasoline, and TT\$ 4.20/liter of premium gasoline (6.5 TT $\$=1$ US $\$$ ). In addition to encouraging energy-wasteful behaviour, the annual subsidy for these fuels was about US $\$ 500$ per person with large quantities of the subsidized diesel fuel being illegally exported. Significant savings can therefore be achieved by converting cars and trucks so that they can use natural gas instead of the afore- mentioned liquid fuels. In addition to the financial benefits accrued by such conversions, the air quality is expected to improve as a result of using the cleanburning fuel and the GHG emissions are lower than those achieved when using the conventional heavier fuels.

The need for promoting such a conversion has been recognized many years before and both CNG and LNG are easily available as a by-product of the existing LNG production facility (used to export 58\% of all the natural gas produced in T\&T). However, the progress achieved on that front has been slow because of the lack of a concerted effort to promote such conversion and the limited number of re-fueling stations equipped to handle CNG.

Following the drop in the price of natural gas and its impact on the country's royalties, this issue is being more seriously addressed. The price of premium gasoline was recently raised to TT $\$ 5.75$ and a plan for increasing the number of stations equipped to handle CNG is being implemented. A growing number of public transport buses are being converted to CNG while the Environmental Management Authority has launched a programme to convert its vehicle fleet to CNG.

This approach is not a novel one since natural gas is a commonly used alternative fuel used by trucks and transit bus fleet operators interested in reducing the cost and environmental impact of their operations. Many factory-built natural gas vehicles are available, which incorporate engine technologies that have been designed specifically for natural gas with power, torque, and fuel efficiency similar to diesel engines. Warranty coverage is also comparable to what is available on diesel engines.

Natural gas presently powers more than 15 million vehicles around the world and the number of natural gas fueled vehicles has been increasing by more than $15 \%$ a year over the past decade (NGV Global, 2012). There are more than 20,000 refueling stations in use globally, with the majority of these stations dispensing CNG, although LNG projects have been announced in several countries for both on-road truck and marine use. The trend of using CNG/LNG to power vehicles is expected to grow as the price differential between natural gas and liquid fuels increases as a result of the abundant availability of natural gas in the market place (Figure 11).

The development of a cost-effective natural-gas 
based alternate to LPG (Liquefied Petroleum Gases that are extensively used in the region for cooking and heating purposes) could similarly benefit NEMA countries that are heavily dependent on the use of this type of fuel for domestic purposes.

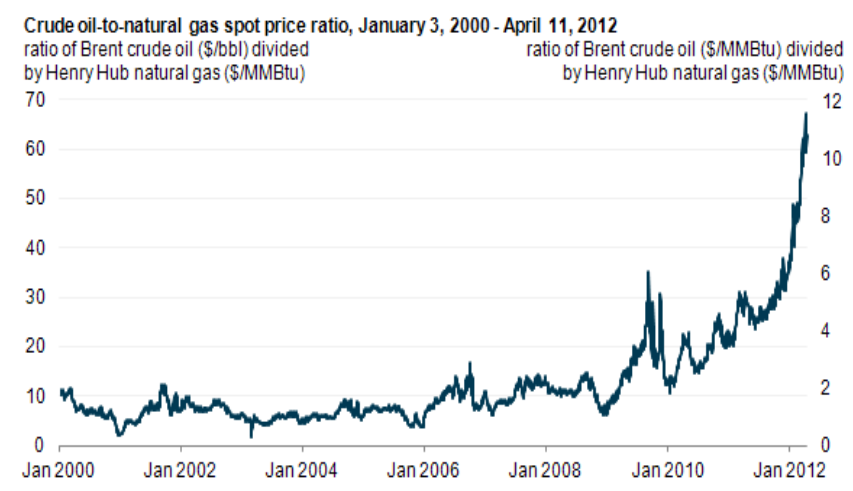

Fig . 11. Price ratio of crude oil to natural gas (U.S. Energy Information Administration)

\section{BALANCING CLIMATE CHANGE ABATEMENT MEASURES AGAINST DEVELOPMENTAL NEEDS}

Global climate change is projected to result in a set of diverse and regionally-specific impacts on natural ecosystems and human societies. A growing literature suggests that while mitigation strategies are necessary, those alone are unlikely to be sufficient to cope with these changes. Therefore, pursuing a complementary strategy of enabling countries to adapt to global change and negate many of the expected adverse impacts is equally, if not more, urgent (Burton et al., 2002; Verner, 2012). However, with about $23 \%$ of MENA's population living on less than $\$ 2$ a day, it is imperative that the climate change management strategies adopted be cost-effective and emphasize economic, social and human development, while addressing the environmental concerns arising from anthropogenic climate change.

Poverty alleviation is often linked to economic development resulting in job creation, increased energy production and consumption, GDP growth, energy security, and reducing all of inequality, which usually translates into increased emissions levels. Policy makers in low-income countries are therefore faced with the dilemma of having to allocate limited resources in an attempt to alleviate poverty while, at the same time, try to slow down GHG emissions. The need for integrating the environment in development planning has been strongly promoted for many years (Tolba M. K., 2008) and it may be now necessary to emphasize the need for integrating development into environmental planning particularly for low- and middle-income countries Over the past few years, several tools have been developed to facilitate rational decision making and achieving a balance between development needs and protecting the environment. (e.g. Low-Emission Development Strategies [LEDS], and Mitigation Action Plans and Scenarios [MAPS]). A detailed discussion of these tools is beyond the scope of this investigation but a quick introduction to their recent application to developing countries was given by Clapp et al. (2010) and Boyd (2013).

Though no formally agreed definition exists, LEDS are generally used to describe forward-looking national economic development plans and strategies that encompass low-emission and/or climate-resilient economic growth. LEDS can serve multiple purposes but are primarily intended to help advance national climate change and development policy in a more coordinated, coherent and strategic manner. By providing integrated economic development and climate change planning, an LEDS can provide valueadded to the myriad of existing climate change and development related strategies and reports that already exist. Because of its benefits, the Copenhagen Accord recognised that a LEDS is indispensable to sustainable development.

\section{FINANCING SUSTAINABLE INTEGRATED DEVELOPMENT PROJECTS WITH CLIMATE CHANGE MITIGATION/ ADAPTATION COMPONENTS}

Achieving sustainable development goals that integrate climate change adaptation/mitigation measures within a holistic framework requires that announced commitments be translated into strategies, policies and actions. The scale of such anticipated efforts in the MENA region requires massive multi-billion dollar financing that needs to be secured from internal and external sources. The financial aspects of climate change issues in the MENA region has recently received much attention from a large number of investigators (Abaza, 2008; Babiker and M. Fehaid, 2011; Fattouh and El-Katiri, 2012; Nakhooda et al., 2012; Saidi, 2012) whose findings provide valuable insight into the real state of affairs. A high level of investment in climate change related projects by resource-rich MENA countries is 
already underway, largely supported with domestic and private sector financing. Many large-scale wind and solar energy projects are also investing in for both domestic use and export, while significant investments are being planned in energy efficiency and carbon reduction projects. However, the financing of similar projects in resource-limited MENA countries faces many challenges.

Climate change funding by international agencies has been rather limited in the MENA region. Although about US\$ 1 Billion in finance has been dedicated since 2004, less than US\$200 million was approved as grants in support of a large number of relatively small-scale projects, which are concentrated in 12 MENA countries (Nakhooda et al., 2012). Similarly, the region's share of the CDM funding is less than $2 \%$ of the global CER market in spite of the multitude of oil, gas, and petrochemical operations that are spread throughout the region and usually offer good opportunities for CDM support.

To further complicate matters, prices for CERs collapsed from about US $\$ 20$ a tonne in 2008 to less than US $\$ 1$ by the end of 2012 . This is mainly driven by the Eurozone debt crisis reducing the industrial activity and the over-allocation of emission allowances under the European Union Emissions Trading Scheme". Furthermore, some of the projects contemplated for support can hardly be considered as being "sustainable" when, for example, the citizens of a developing country end up supporting the development of a promising technology by substantially subsidizing the cost of the power generated over the project's life span (typically 20-30 years in this case).

On the other hand, there exists excellent opportunity for drawing upon the substantial financial resources that are generated within the MENA region itself. These can be utilized to accelerate the development of equitable, holistic, and sustainable climate change projects in the region, provided that a proper framework is developed that secures the equity, longterm viability, and security of such financing efforts. A similar example is presently being considered for the case of the five major emerging national economies of: Brazil, Russia, India, China and South Africa [BRICS], where the need for financial cooperation in the five-nation bloc has led to a recent agreement to establish a BRICS development bank, which could properly utilize the huge savings pool of the bloc countries.

In this regard, it is worthwhile to note that the high oil and gas prices have generated an extraordinary level of international assets and liquidity in the hydrocarbon exporting countries of the MENA region, with gross foreign assets forecast to reach some USD 2.3 trillion by end-2012 (Saidi, 2012). Consequently, governments and corporations in such countries have traditionally been cash rich and not reliant on market financing. However, the global financial crisis, the contagion effects of the Eurozone's continuing crisis and retrenchment of EU banks, along with growing financial sophistication of both the public sector and private businesses in the GCC countries, changed their financial strategy, particularly since the GCC countries are keen to lead in innovative finance as they develop financial centers and diversify their economies (Saidi, 2012).

In this context, Sukuk (Tradable financial instruments that comply with the Islamic law and its investment principles, which prohibit the charging of and/or paying interest) may be a suitable investment instrument for the MENA region, as it would meet the investment requirements of investors from the GCC, Asia and other Shariah-compliant global institutional investors. Several organizations, such as the Green Sukuk Working Group, the Clean Energy Business Council of the MENA Region and the Gulf Bond and Sukuk Association, were formed to address this need (Climatebonds, 2015).

In light of the above, the Clean Energy Business Council of the Middle East and North Africa (CEBC), the Climate Bonds Initiative and the Gulf Bond and Sukuk Association have launched a Green Sukuk Working Group. The group aims to channel market expertise to develop best practices and promote the issuance of sukuk for climate change solutions investments, such as renewable energy and clean tech projects (Saidi, 2012). Green Sukuk are Shariah securities and investments that use criteria for climate solutions developed by the International Climate Bond Standards scheme. The CEBC plans to help investors more easily identify Shariah-compliant opportunities while assisting in providing the investment capital for clean energy and other climatefriendly projects in the region.

Another financing option to be considered is based on the development of a framework by which MENA 
countries with high per capita GHG emissions can gain credit in exchange for financing climate change mitigation/adaptation projects within low- and intermediate-income countries in the region.

\section{BUILDING THE CAPACITY TO MANAGE CLIMATE CHANGE AND DEVELOPMENT CHALLENGES IN MENA}

The development of sustainable solutions to the multitude of climate change issues facing the MENA region requires in-depth knowledge of site-specific conditions prevalent in the various countries and the ability to identify/develop appropriate solutions that can meet the socio-economic needs of the local population. Much of the expertise needed is already available in the region but is scattered amongst many countries, ministries, universities and NGOs. It is therefore necessary to develop a regional network of institutions that have the knowledge and ability to accomplish such goals, and equip it with a project management team that can coordinate the efforts of the various individuals. This network should encourage flexibility in problem-solving, the development of cost-effective innovative approaches, and emphasize the importance of addressing the needs of the various stakeholders and the balance of power among the various interest groups.

Such a network can also draw upon the world-wide pool of expertise, but the translation of the experience of others into a MENA-specific plan of action could best be handled on the local level where the active participation by the various stakeholders (particularly the most vulnerable sectors of the population) is a necessary condition for the success of any sustainable development program.

\section{CONCLUSION}

Based on the analysis presented in this investigation it can be concluded that:

- Socioeconomic analysis of the MENA countries and their GHG emissions shows that they can be split into three categories: the affluent resourcerich countries, the middle-income countries, and a few low-income countries. The former group of countries has the world's highest level of per capita GHG emissions while the latter has almost negligible emissions. Although the variation in per capita GDP amongst these countries is very high, this does not reflect in a similar disparity of human development level.

- Massive investments are needed to accelerate the pace of economic development in lower-and middle income countries in order to improve the standard of living and minimize social disruption. Such efforts will be accompanied by an increase in the emission levels that can be minimized by adopting low emission development strategies and by implementing cost effective means for reducing the emissions associated with the development of the oil/natural gas/petrochemical sectors.

- With about $23 \%$ of MENA's population living on less than $\$ 2$ a day, it is imperative that the climate change management strategies adopted be cost-effective and emphasize economic, social and human development while addressing the concerns arising from anthropogenic climate change. This will avoid duplicating efforts, minimize the capital requirements, and facilitate the acceptance of such measures by the population at large.

- The carbon reduction experience of T\&T clearly identified several negative-cost opportunities for reducing carbon emissions. The savings accrued by implementing such measures can be used for adaptation or economic development purposes. In this fashion, environmental challenges can be turned into economic opportunities and a vehicle for sustainable development.

- Converting cars and trucks so that they can use natural gas instead of gasoline or diesel reduces the GHG emissions and improves the air quality in urban centres. Significant financial benefits can also be accrued by such conversions due to the large difference in the cost per unit energy of the two fuels and the elimination of the subsidies needed to make transportation more affordable. It is, however, essential that such conversion plans be carefully implemented in a fashion that renders it the natural choice of the consumer rather than the socially disruptive price hikes.

- The extent of financial support received from international agencies by MENA countries for 
mitigation/adaptation measures is relatively low. This is most probably driven by the financial difficulties through which some of the world's leading economies are presently going through, a situation, which is not predicted to change in the near future. The region should therefore rely primarily on internally-generated financing driven by intelligent self-motivated interests.

- There apparently is a growing interest in developing Shariah-compliant financing istruments that can be used for climate change solutions investments. This is driven by the high liquidity levels prevalent in the public and private sectors in many resources-rich MENA countries and the desire of the GCC countries to diversify their economies and develop financial centers that lead in innovative finance. This approach is similar to that recently adopted the recent agreement by the BRICS countries to establish their own development bank, which could utilize their huge savings pool to enhance their collective interests.

- An alternate financing scheme may be achieved by having large GHG emitters gain credit for financing climate change mitigation/adaptation projects within low- and intermediate-income countries in the region.

Although no single formula can apply to a collection of countries as diverse as those in the NEMA region, it is recommended that the various MENA countries undertake the initial four steps needed to create a Low-Emission Development strategy [LEDS] which entail:

- Development of vision/goal: An over-arching vision or goal is needed to help guide in the development of long-term policy decisions related to economic development and climate change priorities.

- Assessment of current situation: A clear understanding of major GHG emitting sectors and the socio-economic indicators is fundamental to determining the path forward.

- Emission projections, mitigation potential and costs: Planned pathways for business-as- usual emissions can help provide a sense of the national emission trajectory, while mitigation potential and costs associated with the various emission reduction options are needed as a first step towards identifying promising mitigation actions.

- Vulnerability assessment: Indications of how a country or region may be impacted by climate change can help engage stakeholders, including the general public, and can help identify adaptation needs and the range of possible cost-effective adaptation outcomes.

Much of this information is already available in the many MENA-related studies conducted by several local and international agencies. What is needed is to collect and update the information and ensure its correctness, fill in any gaps, and analyse the findings in a fashion that allows for the identification of costeffective projects that emphasize economic, social and human development while addressing the environmental concerns arising from anthropogenic climate change.

\section{ACKNOWLEDGEMENT}

The financial support of the Natural Sciences and Engineering Research Council of Canada is gratefully acknowledged. The stimulating intellectual input and contribution of all the members of the Trinidad and Tobago Carbon Reduction Strategy Task Force is greatly appreciated.

\section{REFERENCES}

[1] Abaza H., 2008, Financing of Environment Programmes: Private-Public Partnership, in Arab Environment: Future Challenges, M. K. and N. W. Saab Edit., Report of The Arab Forum For Environment And Development, 2008.

[2] Abdel Gelil I., 2009. GHG Emissions: Mitigation Efforts in the Arab Countries, in Arab Environment: Climate Change, M. K. Tolba and N. W. Saab Edit., Report of The Arab Forum For Environment And Development, 2008.

[3] Babiker M. and M. Fehaid, 2011, Climate Change Policy in the MENA Region: Prospects, Challenges, and the implication of Market Instruments, Economic Research Forum paper \# 588. 
[4] Boodlal, D. and A. M. Al Taweel. 2015. Sustainable Reduction of GHG Emissions: The Case of Trinidad and Tobago, Submitted for publication in "Process Safety and Environmental Protection". Institution of Chemical Engineers (UK).

[5] Boyd A., 2013.

http://www.mapsprogramme.org/normalisingapples-and-oranges-comparing-trade-offs-forpro-poor- itigation-options/ (last accessed March 16th, 2013).

[6] Brundtland G.H. et al., 2012, Environment and Development Challenges: The Imperative to Act, Final summary report of the "The Blue Planet Prize laureates" promoted by the Asahi Glass Foundation.

[7] Burton I., S. Huq, B. Lim, O. Pilifosova, and E.L. Schipper. 2002, From impacts assessment to adaptation to adaptation priorities: the shaping of adaptation policy, Climate Policy 2: 145-159.

[8] Cherfane C.C., 2010, Regional Initiatives to Assess the impact of Climate Change on Water Resources, Paper presented at the Arab Water Forum.

[9] Clapp, C., G. Briner, and K. Karousakis, 2010, Low-emission development Strategies (LEDS): Technical, Institutional and policy lessons, Report \# JT03292873, OECD/IEA.

[10] Climatebonds, 2015 , http://www.climatebonds.net/tags/green-sukukworking-group (last accessed on May 20, 2015)

[11] Estiri H., R. Gabriel, E. Howard, L. Wang, 2013, Different Regions, Differences in Energy Consumption- Working Paper no. 134, Center for Statistics and the Social Sciences, University of Washington.

[12] Floyd J. 2012, Beyond this Brief Anomaly- A systemic inquiry into energy and society, (http://beyondthisbriefanomaly.org/; last accessed on May 25th, 2015)

[13] Fattouh, B. and L. El-Katiri, 2012. Energy Subsidies in the Arab World. Arab Human
Development Report, Research Paper Series. United Nations Development Programme, Regional Bureau for Arab States.

[14] Ghaddar N., 2010, Climate Change Research on Energy Efficiency in the Arab Region, Report submitted to the UNDP, Regional Bureau for Arab States (RBAS),

[15] Gomer S. and Lewis A., 2008. An Australian Cost Curve for Greenhouse Gas Reduction. Mckinsey and Company.

[16] Klawitter J., 2011, Implications of Climate Change on Energy and Security in the MENA Region http://www.mei.edu/ , (last accessed March 15th, 2013)

[17] ngv. 2012, http://www.ngv2012.com/ (last accessed March 24th, 2013).

[18] Nakhooda S., A. Caravani, P. Seth and L. Schalatek, 2012. Climate Finance for the Middle East and North Africa: Confronting the challenges of climate change, Heinrich Böll Stiftung North America.

[19] Saidi N. H., 2012, http://hawkamah.org/wpcontent/uploads/2014/10/Harnessing-Green-

Sukuk-for-Sustainable-Development.pdf (last accessed, May 20th, 2015).

[20] Sütterlin B.S., 2012, Segmentation and Characterization of Energy Consumers: Consumer Differences in Energy-Related Behaviours and Commonalities in Perceptions of "Others" Behaviours, Ph.D. Thesis, ETH Zurich Switzerland.

[21] Tolba M. K., 2008, Integrating Environment in Development Planning, in Arab Environment: Future Challenges, M. K. and N. W. Saab Edit., Report of the Arab Forum for Environment And Development, 2008.

[22] Tolba M.K. and N.W. Saab, 2010, Impact of Climate Change on Arab Countries, REPORT OF THE Arab Forum for Environment and Development.

[23] UNDP, 2010, http://hdr.undp.org/en (last accessed May 20th, 2015) 
[24] Ugursal V. I., 2013, Energy Use and Energy Conservation. Chapter 21 in The World Scientific

[25] Handbook of Energy, edited by Gerard $M$ Crawley, World Scientific Publishing Co., 2013.

[26] Verner D. ed. 2012. Adaptation to a Changing Climate in the Arab Countries. Washington, DC: World Bank. DOI: 10.1596/978-0-8213-9458-8.

[27] Wingqvist G. Ö. and O. Drakenberg, 2010,
Environmental and Climate Change Policy Brief - MENA1

[28] World Bank Databank, 2013. http://databank.worldbank.org/ (Last accessed March 18, 2013).

[29] World Bank MENA Region, 2007, Sustainable Development Sector Department (MNSSD) Regional Business Strategy to Address Climate Change Preliminary draft for consultation and feedback. 